\title{
Complex percutaneous coronary intervention of highly calcified distal left main coronary artery supported by percutaneous left ventricular assist device in an octogenarian with severely reduced left ventricular ejection fraction
}

\author{
Wojciech Zimoch ${ }^{1,2}$, Oscar Rakotoarison', Piotr Kubler ${ }^{1,2}$, Michał Kosowski1,2, Artur Telichowski², Krzysztof Reczuch¹,2 \\ 1 Department of Heart Diseases, Wroclaw Medical University, Wrocław, Poland \\ 2 Center for Heart Diseases, 4th Military Hospital, Wrocław, Poland
}

Correspondence to: Oscar Rakotoarison, MD, Department of Heart Diseases, Wroclaw Medical University, ul. Borowska 213, 50-556 Wrocław, Poland, phone: +48717331112 , email: oscar.rakotoarison@gmail.com Received: June 2, 2019. Revision accepted: July 9, 2019. Published online: July 9, 2019. Kardiol Pol. 2019; 77 (9): 881-882 doi:10.33963/KP.14895 Copyright by the Author(s), 2019
An 86-year-old woman with a history of hyperlipidemia, arterial hypertension, and chronic kidney disease was admitted to our hospital to undergo a high-risk percutaneous coronary intervention (PCI). The patient was transferred from a remote hospital where she stayed due to the third nonST-segment elevation myocardial infarction in the previous 4 months. Coronary angiography revealed heavy calcifications in both coronary arteries, a proximally occluded right coronary artery, as well as critical stenosis of the distal left main coronary artery (LCA), ostial left anterior descending artery (LAD), and the left circumflex artery (LCX) (SYNTAX score, 45 points) (FIGURE 1A). The proximal LCX and LAD (functional occlusion) were also significantly narrowed. Ultrasonography showed reduced left ventricular ejection fraction (25\%), with extensive abnormalities in wall motion but preserved viability.

Considering high surgical risk (EuroSCORE II, 15.16\%; Society of Thoracic Surgeons risk score, 9.814\%), the Heart Team referred the patient for a high-risk PCI facilitated by rotational atherectomy and supported by a percutaneous left ventricular assist device (LVAD).

Currently, there are several percutaneous LVADs available. The iVAC2L device (PulseCath, Arnhem, the Netherlands) stands out from other available devices owing to the lower cost and ease of use. The mechanism of the device is based on a 2-way valve integrated into a $17 \mathrm{~F}$ lumen catheter inserted into the left ventricle (FIGURE 1B). The catheter is connected to an extracorporeal 40-cc membrane pump compatible with any standard intra-aortic balloon pump console. In the systolic phase, blood is aspirated from the left ventricle through the tip of the catheter to the membrane pump. During the diastolic phase, the pump directs the blood into the ascending aorta, using the 2-way valve (FIGURE 1 C). This mechanism can secure up to 2 liters of additional cardiac output. As the patient was a slightly built person, we decided that the 2-liter support would be sufficient to safely perform the procedure and the ease of use would reduce the risk of complications.

The procedure was performed under general anesthesia with the surgical preparation of the right femoral artery for percutaneous LVAD insertion. The iVAC2L device was introduced into the left ventricle at the beginning of the procedure. The ostium of the left coronary artery was then intubated with an extra backup 3.5/6F catheter (Medtronic, Santa Rosa, California, United States) introduced via a second arterial approach from the right radial artery. Fielder XT wire (Asahi Intecc, Aichi, Japan) was placed in the distal part of the LAD, which was later exchanged via a Finecross MG microcatheter (Terumo, Tokyo, Japan) to Rota Wire Extra Support (Boston Scientific, Marlborough, Massachusetts, United States). Several runs with a 1.25 burr (Boston Scientific) ${ }^{1}$ were sufficient to modify the calcified plaque 

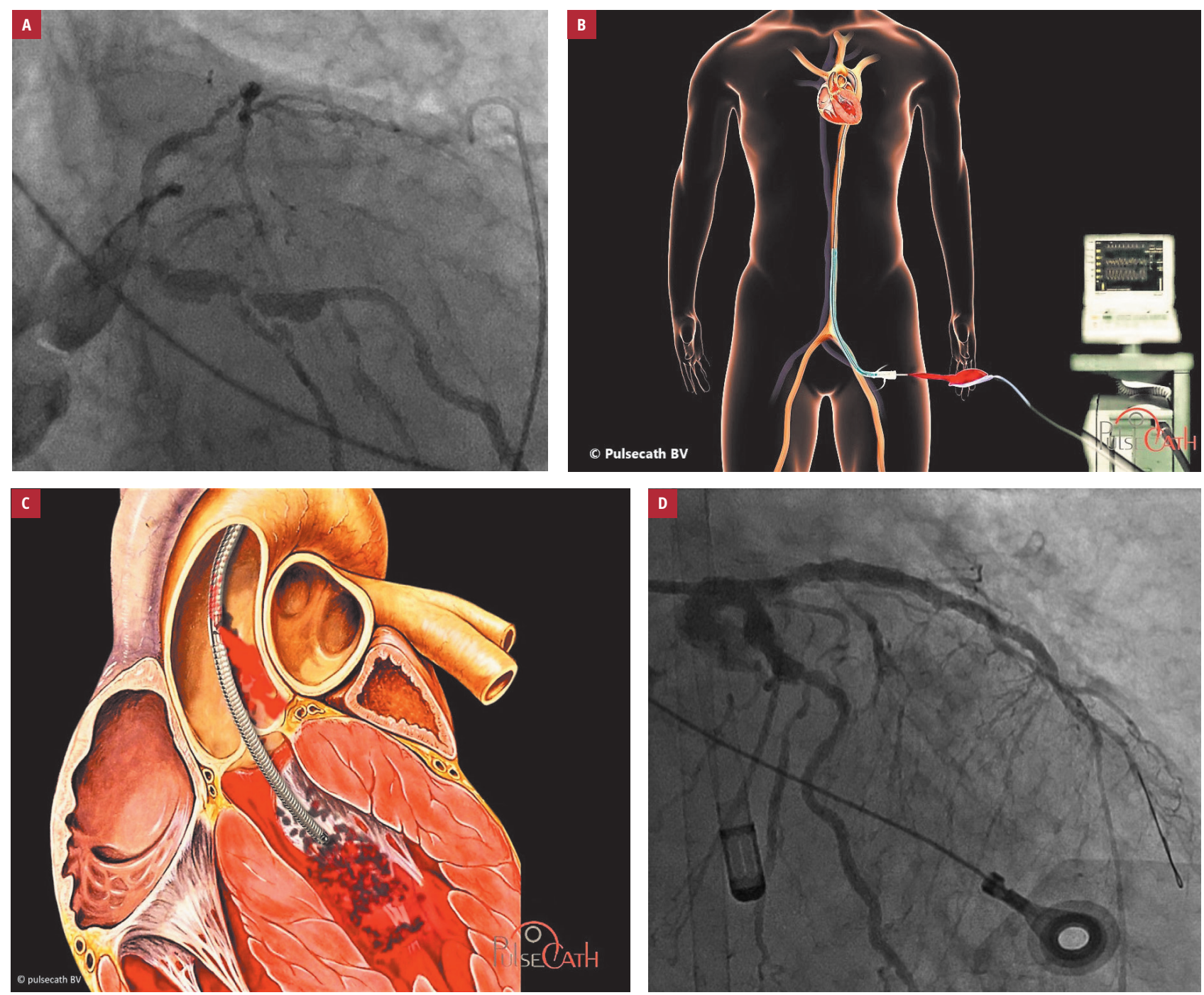

FIGURE 1 A - left coronary artery before the percutaneous coronary intervention; B - iVAC2L system (source, Pulsecath BV); C - iVAC2L catheter (source, Pulsecath BV); D - final result after angioplasty of the medial left anterior descending artery $(L A D)$ and proximal left circumflex artery $(L C X)$, and bifurcation of the left main coronary

artery, LAD, and LCX

and allow a full 2.0/20-mm semicompliant Solarice balloon (Medtronic) expansion. The medial part of the LAD was secured with a 2.5/2-mm Resolute drug-eluting stent (DES; Medtronic). The stenosis in the proximal part of the LCX was predilated with a $2.5 / 12-\mathrm{mm}$ semicompliant Solarice balloon (Medtronic) and secured with a 2.5/9-mm Resolute DES (Medtronic). The bifurcation of the LCA, LAD, and LCX was treated using the culotte technique with 2 Resolute DESs (3.5/34 $\mathrm{mm}$ and 4.0/12 mm; Medtronic). The procedure was finalized by kissing-balloon inflation and proximal optimization treatment in the LCA with a 4.0/8-mm NC Solarice balloon (Medtronic).

The course of the procedure was uneventful, with an optimal angiographic result (FIGURE 1D). The patient remained hemodynamically stable during the whole procedure. The iVAC2L device was removed directly after the procedure, and the access site was secured by the surgeon. Further hospitalization was uneventful, and the patient was discharged in good condition after 3 days.
To our knowledge, this was the first successful procedure with iVAC2L implementation in Poland. The iVAC2L device is user-friendly with a short learning curve. It also ensures sufficient support to perform even highly complicated PCIs in a selected group of patients.

\section{ARTICLE INFORMATION}

\section{CONFLICT OF INTEREST None declared.}

OPEN ACCESS This is an Open Access article distributed under the terms of the Creative Commons Attribution-NonCommercial-NoDerivatives 4.0 International License (CC BY-NC-ND 4.0), allowing third parties to download articles and share them with others, provided the original work is properly cited, not changed in any way, distributed under the same license, and used for noncommercial purposes only. For commercial use, please contact the journal office at kardiologiapolska@ptkardio.pl.

HOW TO CITE Zimoch W, Rakotoarison 0, Kubler P et al. Complex percutaneous coronary intervention of highly calcified distal left main coronary artery supported by percutaneous left ventricular assist device in an octogenarian with severely reduced left ventricular ejection fraction. Kardiol Pol. 2019; 77: 881-882. doi:10.33963/KP.14895

\section{REFERENCES}

1 Dobrzycki S, Reczuch K, Legutko J et al. Rotational atherectomy in everyday clinical practice. Association of Cardiovascular Interventions of the Polish Society of Cardiology: expert opinion. Kardiol Pol. 2018; 76: 1576-1584. 